\title{
Safe Free Tissue Transfer in Patients Older than 90 Years
}

\author{
Marc H. Hohman, MD, FACS ${ }^{1}$ Aurora G. Vincent, MD, FACS ${ }^{2}$ Abdul R. Enzi, MD \\ Yadranko Ducic, MD, FACS ${ }^{2}$ \\ ${ }^{1}$ Department of Facial Plastic and Reconstructive Surgery, Madigan \\ Army Medical Center, Tacoma, Washington \\ 2 Facial Plastic Surgery Associates, Fort Worth, Texas \\ Address for correspondence Aurora Vincent, MD, FACS, Facial Plastic \\ Surgery Associates, 923 Pennsylvania Avenue, Suite 100, Fort Worth, \\ TX 75106 (e-mail: yducic@sbcglobal.net).
}

J Reconstr Microsurg Open 2021;6:e87-e92.

\begin{abstract}
Keywords

- free tissue transfer

- elderly

- osteoradionecrosis

- cancer

- complications

Objective This study aimed to evaluate the safety of microvascular free tissue transfer in the elderly patient population.

Methods We performed a 20-year retrospective review at a tertiary care private practice of patients of $\geq 90$ years of age who underwent microvascular free tissue transfer and had at least 6 months of follow-up. Similarly, we reviewed patients aged 70 to 89 years who underwent free tissue transfer between 2018 and 2020 as a control group. Records were examined for type of flap, defect site, pathology, and occurrence of complications.

Results Overall 77 patients of 90 years or older met the inclusion criteria and 77 sequential patients aged 70 to 89 years were identified to serve as a control group. The overall complication rate among patients of $\geq 90$ years of age was $18 \%$, with flaprelated complications in $4 \%$ (two partial flap loss and one total loss). The mortality rate was $1.3 \%$. All patients of $\geq 90$ years of age undergoing osteocutaneous reconstruction for osteoradionecrosis experienced complications, but only one was a flap complication (partial loss). Among patients aged 70 to 89 years, the overall complication rate was also $18 \%$, with flap-related complications in $4 \%$ (two complete flap failures and one partial loss). The mortality rate in the control group was $2.6 \%$.

Conclusion Soft tissue free flaps are a safe option in the elderly patient population and should be offered to patients who are medically optimized prior to surgery, regardless of age. Osteocutaneous reconstruction for osteoradionecrosis must be undertaken with caution. This study reflects level of evidence 4 .
\end{abstract}

Since the introduction of the radial forearm free flap in 1981 , microvascular tissue transfer has been a mainstay of head and neck reconstruction for defects caused by oncologic ablation, avulsive trauma, osteonecrosis, and various other etiologies. ${ }^{1}$ Its ability to replace multiple different tissue types, and therefore restore form and function, exceeds what is often achieved with local or regional tissue transfer, or with skin grafting. ${ }^{2-6}$ Because these procedures are technically intricate and require meticulous postoperative flap observation and monitoring of the patient in a critical care setting, outcomes are optimized when the procedures are performed by experienced surgeons at high volume centers. ${ }^{7}$ received

February 2, 2021

accepted after revision

May 31, 2021
DOI https://doi.org/

10.1055/s-0041-1736419.

ISSN 2377-0813.

\footnotetext{
(C) 2021. The Author(s).

This is an open access article published by Thieme under the terms of the Creative Commons Attribution-NonDerivative-NonCommercial-License, permitting copying and reproduction so long as the original work is given appropriate credit. Contents may not be used for commercial purposes, or adapted, remixed, transformed or built upon. (https://creativecommons.org/ licenses/by-nc-nd/4.0/)

Thieme Medical Publishers, Inc., 333 Seventh Avenue, 18th Floor, New York, NY 10001, USA
} 
Nevertheless, while flap survival rates are high, 95 to $99 \%$, there are numerous patient factors that have a profound impact on the success of the operation, including history of prior radiation or surgery, nutrition status, cigarette smoking, diabetes, vasculopathy, renal failure, hypothyroidsism, and cardiopulmonary reserve. ${ }^{3,8,9}$

Elderly patients frequently carry many of these comorbidities, and for this reason, some surgeons are reluctant to operate on patients beyond a certain age due to metabolic derangements and limited physiological reserve that may increase the risk of not only flap failure, but patient morbidity and mortality. Declining to consider free flap reconstruction in elderly patients may result in suboptimal reconstructive outcomes, or even settling for palliative care instead of curative surgery. ${ }^{10,11}$ That said, this reticence may be driven by an overabundance of caution rather than a preponderance of evidence, given the paucity of data on the subject; Haughey et al demonstrated in 2001 that age greater than 55 years correlated with higher medical complication rates for microvascular reconstruction patients, but several studies in the intervening years have either refuted this finding or reported that preoperative health status, as expressed using the American Society of Anesthesiologists (ASA) scale, rather than age itself is more predictive of outcomes. ${ }^{3,12-24}$ The majority of these subsequent investigations have placed their threshold for consideration of patients as "elderly" in the 65- to 75-year range, but few authors have had sufficient patient volume to determine flap failure and complication rates in the greater than 90 -year-old population. To elucidate whether there is a higher risk of flap failure and postoperative complications in this patient group, we have performed a retrospective review and analyzed a single surgeon's experience in a high-volume head and neck oncologic surgical practice. Herein, we describe 20 years of the senior author's outcomes after microvascular reconstruction in nonagenarian and centenarian patients, demonstrating flap survival, and complication rates comparable to those expected in younger patients.

\section{Materials and Methods}

We performed a retrospective chart review of patients of 90 years of age and older who underwent free tissue transfer by the senior author (Y.D.) between January 1999 and January 2019. We received approval from the John Peter Smith Institutional Review Board (Fort Worth, TX). We excluded patients who did not have a minimum postoperative followup duration of 6 months. Next, we established a control group of sequential patients aged 70 to 89 years who underwent free tissue transfer by the senior author (Y.D.) between 2018 and 2020. Statistical analyses were performed in Prism 8.2.1 (GraphPad Software, San Diego, CA). Fisher's exact test was used to compare complication rates between patients who underwent osteocutaneous free tissue transfer and those who underwent transfer of soft tissue flaps. Chi-square testing was used to compare complication rates between patients of $\geq 90$ years of age and controls. Alpha was assumed to be 0.05 .

\section{Results}

Seventy-seven patients of $\geq 90$ years of age were identified for inclusion in our study; 43 were female and were 34 were male patients. Ages ranged from 90 to 101 years with a mean of 93.6 years. Fifty-three radial forearm free flaps (RFFF) were performed, as well as seven latissimus dorsi free flaps, seven fibular free flaps (FFF), five rectus abdominis free flaps, three anterolateral thigh (ALT) free flaps, and two scapula free flaps. Recipient sites included the scalp, tongue, cheek, floor-of-mouth, orbit, lateral temporal bone, and mandible. -Table 1 depicts the different types of flaps and transfer locations of each, as well as their complications.

Overall, 14 patients of $\geq 90$ years of age (18\%) experienced a complication after surgery. Seventy-four (96\%) flaps survived completely, but there were three (4\%) flap-related complications. One patient with a FFF experienced loss of the skin paddle; the bone survived, however. Also, one patient with an RFFF experienced partial flap loss, and one ALT was completely lost. The rate of complete flap failure was $1.3 \%$. Six patients developed a wound infection and eventually recovered. Of these six, three had undergone FFF, and one each had undergone scapular free flap, rectus free flap, and RFFF. No complications were observed after soft tissue flap transfer to mucosa-only reconstruction sites.

Five $(6.5 \%)$ patients of $\geq 90$ years of age experienced medical complications after surgery. Two patients

Table 1 Number and type of flaps transferred in the study population with rates of complications

\begin{tabular}{|l|l|l|}
\hline Flap type $(\boldsymbol{n})$ & Recipient site $(\boldsymbol{n})$ & Complication $\boldsymbol{n}(\%)$ \\
\hline RFFF (53) & $\begin{array}{l}\text { Scalp (40), tongue (4), lateral temporal bone/auriculectomy } \\
(3), \text { cheek (2), floor-of-mouth (2), orbit (2) }\end{array}$ & $2(3.8)$ \\
\hline Latissimus (7) & Scalp (7) & $1(14)$ \\
\hline Rectus (5) & Orbit (3), lateral temporal bone/auriculectomy (2) & $2(40)$ \\
& & mortality $^{\text {a }}$ \\
\hline ALT (3) & Lateral temporal bone/auriculectomy (3) & $\begin{array}{l}1(33) \\
\text { Complete flap failure }^{\text {a }}\end{array}$ \\
\hline FFF (7) & & $7(100)^{\text {a }}$ \\
\hline Scapula (2) & Mandible (7) & $1(50)^{\text {a }}$ \\
\hline
\end{tabular}

Abbreviations: ALT, anterolateral thigh flap; FFF, fibular free flap; RFFF, radial forearm free flap.

aThere were significantly more complications among osteocutaneous free flaps than among soft tissue free flaps $(p<0.0001)$. 
Table 2 Complications experienced after free tissue transfer including the flap type and recipient site involved

\begin{tabular}{|l|l|l|l|}
\hline Complication & Number (\%) & Flaps involved & Recipient sites involved \\
\hline Flap failure & $\begin{array}{l}\text { 3 Total (3.9) } \\
\text { 2 partial loss (2.6) } \\
1 \text { complete loss (1.3) }\end{array}$ & FFF, RFFF, ALT & Mandible, lateral temporal bone/auriculectomy \\
\hline Wound infection & $6(7.8)$ & $\begin{array}{l}3 \text { FFF, 1 scapula, } \\
1 \text { rectus, and 1 RFFF }\end{array}$ & $\begin{array}{l}3 \text { Mandible and 3 lateral temporal bone/ } \\
\text { auriculectomy }\end{array}$ \\
\hline MI & $2(2.3)$ & FFF & Mandible \\
\hline Pneumonia & $2(2.3)$ & Rectus and FFF & Orbit, mandible \\
\hline Stroke & $1(1.3)$ & Latissimus & Scalp \\
\hline Death & $\begin{array}{l}1(1.3) \\
\text { Resulting from pneumonia }\end{array}$ & FFF & Mandible \\
\hline
\end{tabular}

Abbreviations: ALT, anterolateral thigh flap; FFF, fibular free flap; MI, myocardial infarction; RFFF, radial forearm free flap.

experienced a myocardial infarction (MI), and both survived. Both of these patients had undergone FFF, one for a defect from squamous cell carcinoma excision and one for osteoradionecrosis (ORN) of the mandible. Two patients developed pneumonia after free tissue transfer. One of these patients had undergone a rectus abdominis free tissue transfer to an orbital defect and survived. The other had undergone FFF transfer for ORN and subsequently expired. This was the only death within the study cohort (1.3\% mortality rate). Finally, one patient experienced a stroke after a latissimus free flap to the scalp but survived. - Table 2 displays the different types of complications observed and flaps and locations in which they occurred.

Among all 14 patients of $\geq 90$ years of age who experienced a complication, eight (57\%) had undergone osteocutaneous free tissue transfer and six (43\%) had undergone soft tissue transfer to cutaneous sites (two RFFF, one ALT, two rectus abdominis, and one latissimus; - Table 3). Among the 14 patients who experienced a complication, seven (50\%) had undergone FFF; every patient who underwent FFF experienced a complication. Also, one (50\%) of the two patients who underwent scapula transfer experienced complications. Thus, eight of nine (89\%) patients who underwent osteocutaneous free tissue transfer experienced a complication. Osteocutaneous flaps were significantly more likely to experience a complication than soft tissue flaps $(p<0.0001)$. Further, osteocutaneous flaps were also significantly more likely to experience a complication than soft-tissue flaps transferred to a mucosal site $(p=0.0014)$. Six patients underwent surgery for osteoradionecrosis, while all others underwent surgery for active cancer. All patients who had
Table 3 Flap transfers by category and type, with their overall (medical and surgical) complication rates

\begin{tabular}{|l|l|l|}
\hline Flap category $(\boldsymbol{n})$ & Flap type $(\boldsymbol{n})$ & Complication $\boldsymbol{n}(\%)$ \\
\hline Mucosa only & RFFF (6) & $0(0)$ \\
\hline Cutaneous & $\begin{array}{l}\text { RFFF (47) } \\
\text { Latissimus (7) } \\
\text { Rectus (5) } \\
\text { ALT (3) }\end{array}$ & $6(9.6)$ \\
\hline Osteocutaneous & $\begin{array}{l}\text { FFF (7) } \\
\text { Scapula (2) }\end{array}$ & $8(88)$ \\
\hline
\end{tabular}

Abbreviations: ALT, anterolateral thigh flap; FFF, fibular free flap; RFFF, radial forearm free flap.

osteoradionecrosis experienced a complication including one death; eight patients undergoing surgery for cancer experienced a complication. Patients with osteoradionecrosis experienced a significantly higher rate of complications $(p<0.0001)$. - Table 4 relates the etiology of the defects to the flaps and their complication rates. A meaningful comparison of complication rates among patients of $\geq 90$ years of age by recipient site and by defect cause (cancer vs. ORN) could not be completed due to small sample sizes.

Next, we identified 77 sequential patients of 70 to 89 years who also underwent free tissue transfer as a control group. Among controls, 18\% (14 patients) experienced some type of complications. There was one (1.2\%) partial flap loss and two (2.5\%) complete flap failures; both flap failures were salvaged with a second flap. The patient with partial flap loss was successfully treated with local tissue rearrangement. Six (7.8\%) patients experienced wound breakdown; three were

Table 4 Etiology of disease with subsequent associated flaps and complications

\begin{tabular}{|c|c|c|}
\hline Indication for surgery & Associated flaps & Complication rate \\
\hline Osteoradionecrosis, 6 & FFF & $\begin{array}{l}100 \% \text { ( } 1 \text { skin paddle loss; } 3 \text { wound infections; } 1 \mathrm{Ml} \\
1 \text { pneumonia leading to death) }\end{array}$ \\
\hline Squamous cell carcinoma, 71 & $\begin{array}{l}\text { RFFF, ALT, rectus, } \\
\text { latissimus, scapula }\end{array}$ & $\begin{array}{l}11 \% \text { ( } 1 \text { partial flap loss; } 1 \text { complete flap loss; } 3 \text { wound infections; } \\
1 \mathrm{Ml} ; 1 \text { pneumonia with recovery; } 1 \text { stroke) }\end{array}$ \\
\hline
\end{tabular}

Abbreviations: ALT, anterolateral thigh flap; FFF, fibular free flap; MI, myocardial infarction; RFFF, radial forearm free flap.

Note: Patients undergoing surgery for osteoradionecrosis experienced significantly more complications $(p<0.0001)$. 
Table 5 Comparison of complication rates between study patients and controls

\begin{tabular}{|l|l|l|l|}
\hline & $\begin{array}{l}\text { Patients } \geq \mathbf{9 0} \text { years } \\
n(\%)\end{array}$ & $\begin{array}{l}\text { Controls } \\
\text { (age: 70-89 years) } \\
\mathbf{n}(\%)\end{array}$ & $\begin{array}{l}\text { Chi-square } \\
\text { comparison (p-value) }\end{array}$ \\
\hline Surgical complications & & & \\
\hline Complete flap failure & $1(1.2)$ & $2(2.5)$ & 0.56 \\
\hline Partial flap failure & $2(2.5)$ & $1(1.2)$ & 0.56 \\
\hline Wound breakdown or infection & $6(7.8)$ & $6(7.8)$ & 1 \\
\hline Perioperative complications & & & \\
\hline Pneumonia & $2(2.5)$ & $2(2.5)$ & 1 \\
\hline MI & $2(2.5)$ & $2(2.5)$ & 1 \\
\hline CVA & $1(1.2)$ & $1(1.2)$ & 1 \\
\hline Overall complications & $14(18)$ & $14(18)$ & 1 \\
\hline Mortality before 6 months & $1(1.2)$ & $1(1.2)$ & 1 \\
\hline
\end{tabular}

Abbreviations: CVA, cerebrovascular accident; MI, myocardial infarction.

treated with conservative wound care, one required a skinmuscle flap, and two required reclosure in the operating room. Two $(2.5 \%)$ patients developed a postoperative pneumonia, two (2.5\%) patients experienced MI, and one (1.2\%) patient suffered a cerebrovascular accident (CVA). The patient who suffered a CVA withdrew care, and one patient who suffered an MI passed away. All other patients were alive at 6-month follow-up. The average length of stay in the hospital among controls was 10.3 days after surgery (range: 6-27).

There was no significant difference in the overall complication rate or flap-associated complication rate between patients of $\geq 90$ years of age and patients of 70 to 89 years of age $(p>0.05)$. - Table 5 compares different types of complications between study patients and controls.

\section{Discussion}

The overall flap survival rate in our series was $96 \%$, identical for the $\geq 90$-year-old group and the control group which is consistent with other authors' reported outcomes in patients of any age group. ${ }^{2-6,24,25}$ Our study is the largest to our knowledge that evaluates patients of $\geq 90$ years of age. In the experience of the authors, many surgeons are reticent to operate on very elderly patients, even if they are otherwise healthy and their wounds are ideal for free tissue reconstruction. Most other authors who have studied outcomes of microvascular free tissue transfer in elderly patients have used a lower threshold to define "elderly," between 65 and 85 years of age, and none has approached the sample size of this study in the nonagenarian patient group. ${ }^{12,14-17,21-24,26-30}$ A 2017 study by Fagin et al also used patients of 90 years of age to define their elderly population, but had a sample size of only 14 patients who underwent free tissue transfer; their findings were consistent with ours, in that outcomes in their older patients were comparable to those of younger patients. ${ }^{13}$

Complication rates reported in the literature vary widely from paper to paper from as low as $10 \%$ to as high as $57 \%$, with medical complications, such as MI and pneumonia, occurring more frequently than surgical complications like flap loss and wound infection. ${ }^{3,20,21,31}$ Mortality rates are also low in the literature, generally in the 1 to $3 \%$ range for patient groups of all ages. ${ }^{2,3,16}$ Arozullah et al found that head and neck surgery in and of itself put patients at increased risk for pulmonary complications, and indeed that was the most common medical complication patients in our series experienced, with pneumonia occurring in 2 out of 77 patients, the same as the number of patients who experienced an MI. ${ }^{32}$ Overall, our elderly patient complication rate of $18 \%$ and mortality rate of $1.3 \%$ fell into the lower end of the ranges reported in the literature; our flap complication rate of $4 \%$ was also consistent with other authors whose rates ran from 0 to $29 \% .^{3,31}$ of note, more than half of the patients in our study underwent RFFF transfer to the scalp, a location that lacks a mucosal suture line and is at less risk of fistula formation. This may account in part for our observed low flap-related complication rate.

Medical complication rates in free flap surgery have been linked to length time under general anesthesia, intraoperative fluid administration volume, diabetes mellitus, need for transfusion, history of hypertension, smoking and alcohol consumption history, and preoperative functional status. $3,15,17,23,24,26,33$ Some authors have linked an increased rate in medical complications to advanced age as well, but Loeffelbein et al and Goh et al have instead correlated advanced age with poorer functional status as an explanation for the apparent connection between age and outcomes. $^{3,26,31,33}$ The only consistently encountered relationship between patient age and outcome is the increased likelihood of discharge to a skilled nursing facility in elderly patients. $^{13,14,21}$

We surmise that our comparatively low medical complication rate of $14 \%$ may result from several factors. Our practice performs a high volume of free flap reconstructions, upward of 200 operations annually, which likely improves outcomes because of the care team's familiarity with 
perioperative management of these patients, even when their ages exceed 90 years. ${ }^{7}$ We thoroughly evaluate our patients preoperatively with a positron emission computed tomography scan to search for metastatic disease, especially in elderly patients to ensure that we are not inadvertently performing palliative surgery with erroneously curative intent. In all patients scheduled for reconstructive surgery, we checked thyroid stimulating hormone and vitamin D levels and attempted to normalize these values before surgical reconstruction. Also, for all patients, we request a cardiology evaluation including an echocardiogram in anyone 90 years of age or older, even without other cardiac comorbidities. This regimen may help to optimize outcomes by minimizing comorbidities preoperatively. Additionally, our patients spend typically 4 to 6 hours of time in the operating room, well below the 500-minute threshold reported by Loeffelbein et $\mathrm{al}^{33}$ which we are able to achieve not only because of our high-volume experience but also through consistent use of a two-team approach for soft tissue resection and reconstruction, and the practice of delaying osteocutaneous tissue transfer for 2 to 3 days after extirpation to confirm negative margins prior to definitive repair.

Notwithstanding the overall low complication rate, we have noticed a higher rate of complications in bony flaps than in soft tissue-only flaps and osteoradionecrosis versus active cancer in our elderly patients. There are varying reports of both higher and lower complication rates in bony flaps compared with soft tissue flaps in the literature, but interestingly, Frederick at $\mathrm{al}^{25}$ in 2014 reported lower complication rates with fibula free flap transfer in general, at $2.9 \%$, but this rate more than doubled to $6.3 \%$ in patients who underwent reconstruction for ORN rather than for oncologic ablation. ${ }^{34-36}$ In our series, we have seen a significantly higher complication rate for patients receiving fibulae for reconstruction after ORN, at 100\% ( - Table 3), but this may be due to the elderly patient population used for this analysis having a higher rate of medical comorbidities. Regardless, there is insufficient literature to answer the question of whether patients receiving osteocutaneous free flaps consistently suffer a higher complication rate if ORN is involved when compared with resection of a primary tumor. It would not be surprising if that proved to be the case, given that radiation therapy has been shown to increase the risk of wound complications, and considering that patients who ultimately develop ORN after radiation therapy may possess some inherent decreased tissue resilience to injury when compared with the general population. ${ }^{8}$

\section{Limitations}

There are several important limitations to our study. First, this is a single-surgeon practice, the results of which may not be generalizable. Next, this is a retrospective review, and the patient cohort may have been influenced by selection bias with sicker patients not having been offered or been more likely to decline surgery. In general, the senior author offers surgery to all patients regardless of age, after a cardiologic evaluation. If the patient is deemed very-high risk from a cardiovascular standpoint, then free flap reconstruction is not pursued. Unfortunately, we do not have survival data beyond the 6-month follow-up period of this study due to patients returning to the care of their referring physicians; longer term survival rates, especially among elderly patients, would have been useful for informing patient care decisions. Further, we do not have data regarding the patients aged 90 years or greater who were evaluated for free flap surgery in the study period and pursued alternative treatment options, nor do we have information on our study patients' comorbidities, functional status, tracheostomy/gastric tube dependence, or quality-of-life measures, and these can also be very important for counseling purposes.

\section{Conclusion}

The data presented herein represent the largest reported series of microvascular free tissue transfer procedures performed in patients of 90 years of age and older, and they demonstrate medical and surgical complication rates, and mortality rates comparable with those of younger patients who have been described in the literature. While osteocutaneous tissue transfer for patients with ORN does have a high complication rate, soft tissue reconstruction in this patient population appears to be very safe, provided care is taken to optimize patients' functional status preoperatively. This is important to recognize to prevent elderly patients from losing the opportunity to undergo curative surgery with state of the art reconstruction for fear of higher complication rates, a fear that can ultimately result in disease progression and the requirement for more aggressive treatment for these patients should they seek care in the future. We feel our study is important in that it highlights the safety of free tissue transfer in patients older than 90 years of age and highlights that surgeons should not shy away from free flaps simply because of a patient's age.

\section{Authors' Contributions}

M.H.H. contributed to manuscript composition and literature review. A.G.V. contributed to manuscript composition and data analysis. A.R.E. contributed to literature review. Y.D. contributed to data collection and manuscript review.

\section{Disclosures}

The authors have no financial conflict to disclose. The work herein does not necessarily represent the views of the U.S. Army or Department of Defense.

Conflicts of Interest

None declared.

\section{References}

1 Yang G, Chen B, Gao Y, et al. Forearm free skin flap transplantation. Zhonghua Yi Xue Za Zhi 1981;61:139-141

2 Suh JD, Sercarz JA, Abemayor E, et al. Analysis of outcome and complications in 400 cases of microvascular head and neck reconstruction. Arch Otolaryngol Head Neck Surg 2004;130 (08):962-966 
3 Haughey BH, Wilson E, Kluwe L, et al. Free flap reconstruction of the head and neck: analysis of 241 cases. Otolaryngol Head Neck Surg 2001;125(01):10-17

4 Spiegel JH, Polat JK. Microvascular flap reconstruction by otolaryngologists: prevalence, postoperative care, and monitoring techniques. Laryngoscope 2007;117(03):485-490

5 Bui DT, Cordeiro PG, Hu QY, Disa JJ, Pusic A, Mehrara BJ. Free flap reexploration: indications, treatment, and outcomes in 1193 free flaps. Plast Reconstr Surg 2007;119(07):2092-2100

6 Rosenthal E, Carroll W, Dobbs M, Scott Magnuson J, Wax M, Peters G. Simplifying head and neck microvascular reconstruction. Head Neck 2004;26(11):930-936

7 Mahmoudi E, Lu Y, Chang SC, et al. Associations of surgeon and hospital volumes with outcome for free tissue transfer by using the national Taiwan population healthcare data from 2001-2012. Plast Reconstr Surg 2017;140(03):455e-465e

8 Nuara MJ, Sauder CL, Alam DS. Prospective analysis of outcomes and complications of 300 consecutive microvascular reconstructions. Arch Facial Plast Surg 2009;11(04):235-239

9 Ishimaru M, Ono S, Suzuki S, Matsui H, Fushimi K, Yasunaga H. Risk factors for free flap failure in 2,846 patients with head and neck cancer: a national database study in Japan. J Oral Maxillofac Surg 2016;74(06):1265-1270

10 Fentiman IS, Tirelli U, Monfardini S, et al. Cancer in the elderly: why so badly treated? Lancet 1990;335(8696):1020-1022

11 de Rijke JM, Schouten LJ, Schouten HC, Jager JJ, Koppejan AG, van den Brandt PA. Age-specific differences in the diagnostics and treatment of cancer patients aged 50 years and older in the province of Limburg, The Netherlands. Ann Oncol 1996;7(07): 677-685

12 Tarsitano A, Pizzigallo A, Sgarzani R, Oranges CM, Cipriani R, Marchetti C. Head and neck cancer in elderly patients: is microsurgical free-tissue transfer a safe procedure? Acta Otorhinolaryngol Ital 2012;32(06):371-375

13 Fagin AP, Gelesko S, Wax MK, Petrisor D. Morbidity and functional outcomes with head and neck free flap reconstruction in patients aged 90 years or older. J Oral Maxillofac Surg 2017;75(07): 1549-1554

14 Weaver TS, Wester JL, Gleysteen JP, Peck JJ, Wax MK. Surgical outcomes in the elderly patient after osteocutaneous free flap transfer. Laryngoscope 2014;124(11):2484-2488

15 Sierakowski A, Nawar A, Parker M, Mathur B. Free flap surgery in the elderly: Experience with 110 cases aged $\geq 70$ years. J Plast Reconstr Aesthet Surg 2017;70(02):189-195

16 Ferrari S, Copelli C, Bianchi B, et al. Free flaps in elderly patients: outcomes and complications in head and neck reconstruction after oncological resection. J Craniomaxillofac Surg 2013;41(02): 167-171

17 Wu Y, Zhang B, Huang Z, Ruan Y, Huang Z. Study of surgical treatment for elderly patients with head and neck cancer. Int J Oral Maxillofac Surg 2018;47(07):824-829

18 Marttila E, Thorén H, Törnwall J, Viitikko A, Wilkman T. Complications and loss of free flaps after reconstructions for oral cancer Br J Oral Maxillofac Surg 2018;56(09):835-840

19 Chen XF, Chen YM, Gokavarapu S, Shen QC, Ji T. Free flap reconstruction for patients aged 85 years and over with head and neck cancer: clinical considerations for comprehensive care. Br J Oral Maxillofac Surg 2017;55(08):793-797

20 Turrà F, La Padula S, Razzano S, et al. Microvascular free-flap transfer for head and neck reconstruction in elderly patients. BMC Surg 2013;13(Suppl 2):S27
21 Mitchell CA, Goldman RA, Curry JM, et al. Morbidity and survival in elderly patients undergoing free flap reconstruction: a retrospective cohort study. Otolaryngol Head Neck Surg 2017;157(01): 42-47

$22 \mathrm{Kim} \mathrm{H}, \mathrm{Kim} \mathrm{SD}$, Shim YJ, et al. Is there any age cutoff to treat elderly patients with head and neck cancer? Comparing with septuagenarians and octogenarians. J Korean Med Sci 2016;31(08): 1300-1306

23 Reiter M, Baumeister P, Jacobi C. Head and neck reconstruction in the elderly patient: a safe procedure? Eur Arch Otorhinolaryngol 2017;274(08):3169-3174

24 Serletti JM, Higgins JP, Moran S, Orlando GS. Factors affecting outcome in free-tissue transfer in the elderly. Plast Reconstr Surg 2000;106(01):66-70

25 Frederick JW, Sweeny L, Carroll WR, Peters GE, Rosenthal EL. Outcomes in head and neck reconstruction by surgical site and donor site. Laryngoscope 2013;123(07):1612-1617

26 Goh CS, Kok YO, Yong CP, et al. Outcome predictors in elderly head and neck free flap reconstruction: a retrospective study and systematic review of the current evidence. J Plast Reconstr Aesthet Surg 2018;71(05):719-728

27 Wähmann M, Wähmann M, Henn D, et al. Geriatric patients with free flap reconstruction: a comparative clinical analysis of 256 cases. J Reconstr Microsurg 2020;36(02):127-135

28 Patel VM, Stern C, Miglani A, et al. Evaluation of the relationship between age and outcome after microvascular reconstruction among patients with recurrent head and neck squamous cell carcinoma. J Reconstr Microsurg 2017;33(05):336-342

29 Bhama PK, Patel SA, Khan U, Bhrany AD, Futran ND. Head and neck free flap reconstruction in patients older than 80 years. J Reconstr Microsurg 2014;30(08):523-530

30 Spyropoulou GA, Jeng SF, Hsieh CH, Tsimponis A, Shih HS. Microsurgical reconstruction for head and neck cancer in elderly patients. J Reconstr Microsurg 2014;30(02):91-96

31 Howard MA, Cordeiro PG, Disa J, et al. Free tissue transfer in the elderly: incidence of perioperative complications following microsurgical reconstruction of 197 septuagenarians and octogenarians. Plast Reconstr Surg 2005;116(06):1659-1668, discussion 1669-1671

32 Arozullah AM, Daley J, Henderson WG, Khuri SFThe National Veterans Administration Surgical Quality Improvement Program. Multifactorial risk index for predicting postoperative respiratory failure in men after major noncardiac surgery. Ann Surg 2000;232 (02):242-253

33 Loeffelbein DJ, Julinek A, Wolff KD, Kochs E, Haller B, Haseneder R. Perioperative risk factors for postoperative pulmonary complications after major oral and maxillofacial surgery with microvascular reconstruction: a retrospective analysis of 648 cases. J Craniomaxillofac Surg 2016;44(08):952-957

34 Lin JAJ, Loh CYY, Tsai CH, Chang KP, Wu JC, Kao HK. Free flap outcomes of microvascular reconstruction after repeated segmental mandibulectomy in head and neck cancer patients. Sci Rep 2019;9(01):7951

35 Chaine A, Pitak-Arnnop P, Hivelin M, Dhanuthai K, Bertrand JC, Bertolus C. Postoperative complications of fibular free flaps in mandibular reconstruction: an analysis of 25 consecutive cases. Oral Surg Oral Med Oral Pathol Oral Radiol Endod 2009;108(04): 488-495

36 Kroll SS, Schusterman MA, Reece GP, et al. Choice of flap and incidence of free flap success. Plast Reconstr Surg 1996;98(03): 459-463 